\title{
EDUCAÇÃO E CONSCIENTIZAÇÃO: CONTRIBUIÇÕES DE PAULO FREIRE À DEMOCRACIA
}

\section{Danilo Trombetta Neves}

Discente do Programa de Pós-graduação em Educação da Faculdade de Ciência e Tecnologia de Presidente Prudente/SP - FCT / UNESP e Professor do Programa de Pós-graduação em Direito da UNOESTE. E-mail: danilotn@hotmail.com.

\section{RESUMO}

Partindo da problemática do empobrecimento da democracia, o artigo objetiva resgatar conceitos e práticas veiculadas pelo educador Paulo Freire com enfoque nas possíveis interferências e contribuições da educação. Considerando que o poder emana do povo e há de ser exercido, direta ou indiretamente, pelo povo e em proveito do povo, a ênfase freireana de que o educador e a educação não podem ser neutros politicamente remete a uma reflexão e projeta qual o tipo de aluno e cidadão existentes e em formação. Acredita-se, nesta perspectiva, que a educação enquanto mecanismo de desenvolvimento do ser humano (ser mais) propicia condições para a tomada de consciência crítica. A consciência crítica, por sua vez, atua como elemento facilitador da participação política e popular. Esta participação consolida o exercício da democracia.

Palavras-chave: Educação. Conscientização. Povo. Participação Popular. Democracia.

\section{MÉTODO}

Para cumprir com os objetivos propostos, o presente trabalho seguirá os métodos dedutivo, histórico e comparativo, com emprego de pesquisa documental e bibliográfica.

\section{INTRODUÇÃO}

Em pleno século XXI o Brasil ainda reflete sobre seu processo de democratização e alguns alicerces institucionais.

Um dos pontos determinantes para a concretização do Estado Democrático de Direito preconizado pela Constituição Federal de 1988 é a participação popular. Esta, por sua vez, é impulsionada com a formação de consciência e sensibilização social e política. Nesse sentido, a educação preconizada por Paulo Freire, com um viés eminentemente político, muito tem a contribuir, razão pela qual o tema é explorado.

Por outro lado, a temática da educação também é alvo do mercado, sobre outra perspectiva, qual seja, a melhoria da mão-de-obra como possibilidade de aumento da produção e do crescimento econômico.

Assim, percebe-se a corrida pela expansão da educação, até anteriormente vista como democratização do ensino, agora como oportunidade de enriquecimento e massificação do aprendizado. 
Os gestores da educação e os educadores propriamente ditos necessitam retomar toda a amplitude do conceito de qualidade da educação, com observância obrigatória da bandeira defendida por Paulo Freire quanto ao papel político intrínseco no ato de educar.

As palavras apresentadas almejam uma aproximação e ao mesmo tempo uma redescoberta da importância da educação para o fortalecimento da práxis democrática.

\section{BREVES PALAVRAS SOBRE DEMOCRACIA}

Democracia é conceito histórico, não sendo um valor em si mesmo, mas meio e instrumento de realização de valores essenciais de convivência humana. Sua historicidade se relaciona com os direitos fundamentais da humanidade, mantendo sempre o princípio básico de que revela um regime político em que o poder repousa na vontade do povo.

Ressalte-se que a democracia não é um mero conceito político abstrato e estático, mas é um processo de afirmação do povo e de garantia dos direitos fundamentais que o povo vai conseguindo no correr da história.

Nesse processo vai-se configurando também a noção histórica de povo. Para BURDEAU (1960, pp. 29/30), "se é verdade que não há democracia sem governo do povo pelo povo, a questão importante está em saber o que é preciso entender por povo e como ele governa".

A concepção de povo tem variado com o tempo, porque, se sempre é o povo que governa, não é sempre o mesmo povo. Por isso é que a democracia da antiguidade grega não é a mesma dos tempos modernos; nem a democracia burguesa capitalista corresponde à democracia popular.

Governo do povo significa que este é fonte e titular do poder (todo poder emana do povo), de conformidade com o princípio da soberania popular que é o princípio fundamental de todo regime democrático.

Governo pelo povo quer dizer governo que se fundamenta na vontade popular, que se apoia no consentimento popular; governo democrático é o que se baseia na adesão livre e voluntária do povo à autoridade, como base da legitimidade do exercício do poder, que se efetiva pela técnica da representação política (o poder é exercido em nome do povo).

Governo para o povo há de ser aquele que procura liberar o ser humano de toda imposição autoritária e garantir o máximo de segurança e bem-estar.

Noutro giro, é sabido que o povo há de ser concebido como o conjunto de indivíduos concretos, situados, com suas virtudes e defeitos, e não como entes abstratos. 
Para o doutrinador constitucionalista JOSÉ AFONSO DA SILVA, a democracia é um processo de convivência social em que o poder emana do povo, há de ser exercido, direta ou indiretamente, pelo povo e em proveito do povo (1995, p. 127).

O autor acima mencionado apresenta dois princípios fundamentais da democracia, que the imprime a essência conceitual: (a) o da soberania popular, segundo o qual o povo é a única fonte do poder, que se exprime pela regra de que todo o poder emana do povo; (b) a participação, direta ou indireta, do povo no poder, para que este seja efetiva expressão da vontade popular; nos casos em que a participação é indireta, surge um princípio derivado ou secundário: o da representação.

As técnicas que a democracia usa para concretizar esses princípios têm variado, e certamente continuarão a variar, com a evolução do processo histórico, predominando, no momento, as técnicas eleitorais com suas instituições e o sistema de partidos políticos, como instrumentos de expressão e coordenação da vontade popular (SILVA, 1995, p. 132).

$\mathrm{Na}$ Tradição Romano-Medieval da soberania popular o príncipe tem autoridade/poder porque o povo lha deu. A fonte originária deste poder seria sempre o povo, abrindo caminho para a distinção entre a titularidade e o exercício do poder. A concessão temporária e revogável, em princípio, ensina que a titularidade do poder teria permanecido no povo e ao príncipe seria confiado apenas o exercício do poder (BOBBIO, 2004, p. 321).

Frise-se que a democracia política é estéril a menos que seja acompanhada pelo poder em outras esferas, principalmente na área da economia (BLACKBURN, 1997, p. 92).

Em síntese, a democracia, como regime político, é o governo do povo, pelo povo e para o povo.

\section{EDUCAÇÃO E CONSCIENTIZAÇÃO}

A Educação em Paulo Freire, desde os primeiros registros, esteve ligada com a superação da opressão, por meio da tomada de consciência. Esta tomada de consciência almejada na prática pedagógica deveria contribuir com o conhecimento de si mesmo, por parte do educando, bem como conhecimento do outro e do mundo.

Nesse sentido, a pedagogia do oprimido, como pedagogia humanista e libertadora, está focada em duas situações. A primeira diz respeito ao processo em que os oprimidos vão desvelando o mundo da opressão e vão comprometendo-se com a práxis, com a sua transformação; a segunda, em que, transformada a realidade opressora, esta pedagogia deixa de 
ser do oprimido e passa a ser a pedagogia dos homens em processo de permanente libertação (FREIRE, 1975, p. 44).

Frise-se que na resposta dos oprimidos à violência dos opressores é que se encontra o gesto de amor. Consciente ou inconscientemente, o ato de rebelião dos oprimidos, que é sempre tão ou quase tão violento quanto a violência que os cria, pode inaugurar o amor.

Enquanto a violência dos opressores faz dos oprimidos homens proibidos de ser, a resposta destes à violência daqueles se encontra infundida do anseio de busca do direito de ser. Os opressores, violentando e proibindo que os outros sejam, não podem igualmente ser; os oprimidos, lutando por ser, ao retirar-Ihes o poder de oprimir e de esmagar, lhes restauram a humanidade que haviam perdido no uso da opressão.

Freire insiste que somente os oprimidos, libertando-se, podem libertar os opressores. Estes, enquanto classe que oprime, nem libertam e nem se libertam.

Assim, o importante, por isto mesmo, é que a luta dos oprimidos se faça superar a contradição em que se acham. Que esta superação seja o surgimento do homem novo - não mais opressor, não mais oprimido, mas homem libertando-se (FREIRE, 1975, p. 46).

Deste modo, reconhece-se que na superação da contradição opressores-oprimidos, que somente pode ser tentada e realizada por estes, está implícito o desaparecimento dos primeiros, enquanto classe que oprime.

Para tal superação clarifica que a realidade não deve ser para os oprimidos um "mundo fechado" (em que se gera o medo da liberdade), mas uma situação que apenas os limita e que eles podem transformar.

É importante que ao reconhecerem o limite que a realidade opressora lhes impõe, tenham, neste reconhecimento, o motor de sua ação libertadora.

De outra parte, o opressor, descobrindo-se nesta condição, mesmo que sofra por este fato, não se solidarizará com os oprimidos ao menos que se envolva com estes numa perspectiva emancipadora.

Solidarizar-se com estes é algo mais que prestar assistência, mantendo-os atados, contudo, à mesma posição de dependência. A solidariedade, exigindo de quem se solidariza que "assuma" a situação de com quem se solidarizou, é uma atitude radical (FREIRE, 1975, p. 37).

Esta solidariedade exige atitudes concretas e permanentes de reconhecimento e em direção ao outro.

Por esta razão, Paulo Freire aponta que: 
"Uma das tarefas mais importantes da prática educativo-crítica é propiciar as condições em que os educandos em suas relações uns com os outros e todos com o professor ou a professor ensaiam a experiência profunda de assumir-se. Assumir-se como ser social e histórico, como ser pensante, comunicante, transformador, criador, realizador de sonhos, capaz de ter raiva porque capaz de amar. A assunção de nós mesmos não significa a exclusão dos outros. É a 'outredade' do 'não eu', ou do tu, que me faz assumir a radicalidade do meu eu (FREIRE, 1996, p. 46).

Neste contexto, as diferenças dos educandos necessitam ser contempladas para que a realidade, desnudada, possa ser confrontada e reinventada. Importa uma formação permanente que se funde, sobretudo, na reflexão sobre a prática (FREIRE, 2006, p. 25).

Portanto, a educação focada na conscientização e superação das desigualdades gerará um maior senso de pertencimento ao "povo", este detentor do poder e dos rumos de uma nação.

\section{CONTRIBUIÇÕES DE PAULO FREIRE À DEMOCRACIA}

Ao estabelecer uma ligação e um apelo ao compromisso entre educação e política, Paulo Freire questiona os papéis sociais e as possibilidades de mudanças na estrutura vigente. Sua ênfase não está na transmissão pura e simples de conhecimentos, muito menos num letramento servil.

Sua proposta exprime uma ampliação do ser(mais) ao proporcionar, por meio da educação, novas possibilidades do indivíduo se conhecer e conhecer o contexto em que inserido.

A abordagem da libertação evidencia a questão política na medida em que existe uma preocupação de resgate da dignidade humana, relacionada com a participação e engajamento no momento histórico.

O "povo" necessita enxergar-se como elemento fundante da nação. Não apenas isso, mas de que é o detentor de todo o poder. Nesta perspectiva, a educação é um dos principais instrumentos para o envisionamento e participação popular.

Partindo do letramento, que poderá ocorrer dentro de um procedimento de reflexão e elementos do contexto, como proposto em seu método, Paulo Freire está sempre enfatizando o empodeiramento. Este termo, ainda que não cunhado pelo referido educador, com ele se identifica na medida em que cria povo consciente e sabedor de que detêm o poder.

Para dizer, povo consciente é povo que conhece seus direitos e os reivindicam, como titulares e beneficiários do poder/Estado. 
A mudança da realidade pertence a todos que a percebem e a todos que se percebem autores de suas histórias.

No campo da política, onde se situa a democracia aqui narrada, a educação marcada pela conscientização deve impulsionar o indivíduo-cidadão a reconhecer seu papel e empenhar-se no processo histórico e contínuo de quebra de paradigmas e da cadeia de dominação, fazendo com que o ente público e o Estado como um todo sirva ao próprio povo, e não a uma minoria.

Quando o povo estiver convicto de que é o titular do poder e de que o governo deve ser exercido em seu favor, posturas e seguimentos da sociedade repensarão o quê e para quem estão labutando.

A ênfase freireana de que o educador e a educação não podem ser neutros politicamente remete a uma reflexão e projeta qual o tipo de aluno e cidadão que teremos.

Nesse sentido, a educação enquanto mecanismo de desenvolvimento do ser humano (ser mais) propicia condições para a tomada de consciência crítica.

Uma população com consciência crítica, por sua vez, prima pela participação política e popular. Esta participação consolida o exercício da democracia.

Conclui-se, então, que a democracia guarda relação ou pode ser influenciada pela educação, mormente quando esta é desenvolvida numa perspectiva de conscientização e emancipação-libertação. Por meio de uma educação politizada pode-se, sim, resgatar o conceito de povo, enquanto detentor, agente e beneficiário do poder, alterando-se diversas estruturas e mecanismo estatais, como conseqüência de uma democracia consolidada.

\section{REFERÊNCIAS BIBLIOGRÁFICAS}

BLACKBURN, Simon. Dicionário Oxford de Filosofia. Rio de Janeiro, Jorge Zahar Editor, 1997.

BOBBIO, Norberto (org). Dicionário de Política. 12 ed. Brasília, Universidade de Brasília, v. 1, 2004.

BURDEAU, Georges. La democracia. Caracas/Barcelona, Ariel, 1960.

FREIRE, Paulo. Pedagogia do oprimido. 3 ed. Rio de Janeiro, Paz e Terra, 1975.

Pedagogia da autonomia. 23 ed. Rio de Janeiro, Paz e Terra, 1996.

A educação na cidade. 7 ed. São Paulo, Cortez, 2006.

SILVA, José Afonso da. Curso de Direito Constitucional Positivo. 10 ed. São Paulo, Malheiros Editores, 1995. 